\title{
SOBRE O PROBLEMA DA AUTONOMIA DA ARTE E SUAS IMPLICACÕES HERMENÊUTICAS E ONTOLÓGICAS
}

\author{
Sandra Abdo* \\ sandraabdo@uol.com.br
}

RESUMO $O$ presente artigo discute o problema da autonomia da arte $e$ suas implicações hermenêuticas e ontológicas, tomando por base as concepções de Herbert Marcuse e de Luigi Pareyson.

Palavras-Chave Arte; Autonomia; Marcuse; Pareyson

ABSTRACT This article discusses the problem of artistic autonomy and its hermeneutic and ontological implications from the point of view of Herbert Marcuse's and Luigi Pareyson's theory.

Keywords Art; Autonomy; Marcuse; Pareyson

\section{Introdução}

O conceito de autonomia da arte, embora recorrente nas teorias estéticas do século $\mathrm{XX}$, ainda suscita controvérsias, sobretudo no que diz respeito às implicações hermenêuticas e ontológicas dos diversos enfoques adotados. Neste trabalho, discuto alguns aspectos dessa questão, tomando como referência as concepções de Herbert Marcuse e de Luigi Pareyson. Meu fio

\footnotetext{
* Professora do Departamento de Filosofia da Universidade Federal de Minas Gerais. Artigo recebido em 15/09/05 e aprovado em 15/11/05.
}

KRITERION, Belo Horizonte, $n^{0}$ 112, Dez/2005, p. 357-366 
condutor é a idéia de que, embora concordem quanto a uma radical defesa da autonomia da arte, essas duas teorias se ancoram em uma fundamentação bem diversa, daí decorrendo implicações hermenêutico-ontológicas que merecem ser discutidas.

\section{Marcuse: a concepção de obra de arte como "conteúdo tornado forma"}

Nos escritos de sua última fase, notadamente em $A$ dimensão estética, Marcuse critica a ortodoxia predominante da estética marxista, posicionandose contra a excessiva ênfase dessa estética no caráter de classe da produção artística e a conseqüente redução da arte a ideologia. Contra essa visão, Marcuse salienta a radical transcendência da arte à sua determinação histórico-social. Delineio, a seguir, alguns de seus argumentos centrais.

A grande arte, a arte autêntica, é revolucionária, subversiva da percepção e da compreensão. Mas, mesmo podendo representar a visão de uma determinada classe social, ela tem o seu potencial político e revolucionário nela mesma, quer dizer, não apenas no que diz, mas também “(...) no modo como diz". ${ }^{1}$ A arte tem, portanto, o poder de representar a predominante ausência de liberdade dos indivíduos em uma sociedade sem liberdade e, ao mesmo tempo, de promover uma ruptura "(...) com a realidade social mistificada (e petrificada) (...), abrindo os horizontes da mudança (libertação)". ${ }^{2}$ Mas pode fazê-lo, unicamente, “(...) em virtude da forma dada ao conteúdo" (entendendose, aqui, como conteúdo, as relações sociais existentes e, como forma, o resultado da "transformação estética" por que passa esse conteúdo). Dizendo de outro modo, o potencial político, subversivo e libertário da arte baseia-se unicamente na sua dimensão estética, o que significa que ela exerce todas essas funções "(...) só em referência a si própria, como conteúdo tornado forma". ${ }^{3}$ É claro, há uma diferença na representação desse potencial, e essa diferença é determinada pelas diferentes condições sociais, que se fazem presentes na obra de maneiras diversas, mas sempre como “(...) expressões e manifestações históricas específicas da mesma substância trans-histórica da arte: a sua própria dimensão de verdade, protesto e promessa, constituída pela forma estética". ${ }^{4}$

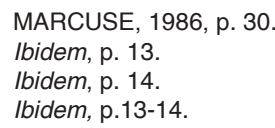


Sem dúvida, o texto de Marcuse faz uma eloqüente defesa da autonomia da arte, tendente mesmo, para muitos, a um inquietante formalismo estético. Resta, todavia, saber se seus argumentos podem de fato sustentar suas teses. É este o ponto que pretendo aqui discutir.

Marcuse, como vimos, partindo de um modelo analítico predominantemente fundacionalista, define a obra de arte por referência a um fundo mais amplo - as relações sociais existentes - no qual é inserida. A obra de arte surge, então, como resultado da transformação desse conteúdo preexistente, pré-artístico. Uma vez transformado esteticamente, esse conteúdo dará lugar a uma outra realidade, autônoma e qualitativamente diferente - a forma artística ${ }^{-}$, aparecendo, portanto, na obra de arte, de modo alienado e mediatizado, necessariamente estilizado, remodelado, destituído da sua imediatidade, de modo a atender à exigência da "lei da forma estética".

Mas que lei é esta, afinal? E, mais precisamente, como ela de fato opera enquanto reguladora da dita "transformação"? A pergunta procede, uma vez que Marcuse apenas alude à existência da referida lei, mas não a problematiza verdadeiramente. Sendo de cunho sociológico a sua preocupação central, ele passa rapidamente à explicação do que seria o nomos da arte, segundo ele, a negação das relações sociais estabelecidas.

Ora, assim postos os termos da questão, em que consiste, então, o êxito da arte como tal? Digo, não o seu êxito como instrumento político, mas o seu êxito como arte, o seu ser arte, enfim? Mais uma vez, parece-me dúbia a resposta de Marcuse, para não dizer, de todo incoerente. Ele aventa a existência de uma lei da forma estética, identifica-a como elemento decisivo para a autonomização da arte, mas, logo em seguida, submete-a ao êxito de uma função política, mediante a qual a arte se investiria de um duplo caráter, negativo e afirmativo, no sentido de que, de um lado, se assentaria na realidade existente, representando-a e afirmando-a; de outro, transcenderia e denunciaria essa realidade, expressando uma verdade antagônica que constitui a sua outra face.

Volto ao ponto que me parece mais problemático nessa teoria: a impossibilidade de uma explicação consistente sobre a passagem do conteúdo para o plano da arte, impossibilidade esta que atinge não apenas a sua teoria, mas todas aquelas que, ancoradas em resíduos proto-hegelianos, entendem a arte como formação/transformação de um dado conteúdo. Não é difícil perceber que tal definição institui, já na base do processo explicativo, um hiato temporal entre a forma resultante e o "conteúdo" extra-artístico a que ela se refere, não só no sentido de que subentende uma prioridade temporal desse conteúdo, mas também de que o mesmo acaba por ganhar uma preeminência qualitativa. O resultado é o comprometimento da unidade de forma e conteúdo, já na base 
da explicação, impasse que não se resolve com a simples afirmação de que "Na obra de arte, a forma torna-se conteúdo e vice-versa". ${ }^{5}$ O próprio uso do verbo "tornar" já reforça a idéia de uma seqüência temporal entre os dois processos.

Marcuse tenta driblar o problema, importando da teoria psicanalítica o conceito de sublimação, muito em voga na cultura de então. A "transformação estética" se operaria mediante uma sublimação das condições sociais existentes — os dados imediatos seriam estetizados, incorporando-se à obra como algo qualitativamente diferente, parte de outra realidade. Coerentemente com esse quadro explicativo, a função revolucionária e libertária da arte passa a ser explicada como um poder de operar uma "dessublimação na percepção dos indivíduos — nos seus sentimentos, juízos, pensamentos", daí resultando a invalidação das normas, necessidades e valores dominantes, ou seja, a destruição da "(...) objetividade reificada das relações sociais estabelecidas (...)", e ao mesmo tempo, a abertura de "(...) uma nova dimensão da experiência: o renascimento da subjetividade rebelde". ${ }^{6}$ O que vem à tona, ao fim e ao cabo, é, segundo Marcuse, a essência da realidade estabelecida, as potencialidades reprimidas do homem e da natureza, residindo a verdade própria da arte no fato de a realidade ser tal como nela aparece.

A esta altura, creio que já se delineia com clareza o que desejo salientar. Afinal, o que de fato esclarecem sobre a especificação da arte e, conseqüentemente, sobre a sua autonomia, conceitos como sublimação, dessublimação e outros tantos a que Marcuse recorre no decorrer de sua exposição? São conceitos científicos, sim, mas que constituem verdadeiros termos-guarda-chuva, capazes de abrigar produções humanas de natureza inteiramente diversa, sem nada dizerem de específico sobre nenhuma delas. Em suma, são conceitos genéricos, que nada dizem de específico sobre a arte como tal. E o que é mais grave: tratam-na como um resultado, uma decorrência de causas externas, esvaziando, assim, a sua novidade e o seu estatuto próprio.

\section{Pareyson: a concepção de obra de arte como êxito de uma especificação formativa}

Vejamos agora uma outra concepção, oferecida pela "estética da formatividade", de Luigi Pareyson, segundo a qual a arte se define como puro êxito de uma atividade plasmadora.

5 MARCUSE, 1986, p. 50 (grifo meu).

6 Ibidem, p. 20-21. 
Pareyson, diferentemente de Marcuse, faz da própria especificação da forma artística o centro do seu conceito de autonomia da arte, desenvolvendo a partir daí uma estética de feição inequivocamente ontológica. Sua explícita intenção é justamente evitar o beco sem saída em que se confinam tanto aquelas teorias que se perdem na exaltação de um vazio formalismo, quanto aquelas que tomam como ponto de partida um suposto conteúdo da obra de arte e, depois, não têm como explicar consistentemente a crucial passagem do mesmo ao plano da arte.

Mas o que Pareyson de fato entende por forma artística e sobre como esta se especifica? Em arte, explica ele, a forma se especifica como um puro êxito, quer dizer, como acabamento de um processo cuja única condição de êxito é a sua adequação consigo mesmo (e não a algum fim ou valor extrínseco). Sobre esse ponto, ele faz alguns importantes esclarecimentos, cujo teor resumo a seguir.

Primeiramente, a especificação formativa não subentende o exercício isolado de uma formatividade vazia (até porque isto seria impossível, considerando-se que a pessoa se faz sempre inteiramente presente em todos os seus atos), mas, pelo contrário, requer, para a sua sustentação, toda a plenitude da vida espiritual de quem opera, toda a sua vontade expressiva e comunicativa, traduzidas em modo de formar. É assim, portanto, quer dizer, já como componente orgânico da obra de arte, que o mundo do artista se faz presente na obra.

Esse conceito de modo de formar permite entender o caráter autoreferencial do discurso artístico, enquanto discurso originador, que se constitui não somente como discurso sobre, mas, primordialmente, como fundador de uma linguagem e, portanto, de um mundo próprio que com ele se origina. $\mathrm{O}$ discurso primeiro de uma obra de arte é, pois, aquele que ela faz dispondo suas formas de um modo específico - e não simplesmente o conjunto de juízos que ela eventualmente pronuncia sobre determinado assunto. $\mathrm{O}$ seu legítimo conteúdo revela-se, então, o seu próprio modo de formar, enquanto modo de ver a realidade e de atuar sobre ela. É desse prisma que Pareyson teoriza a questão da autonomia da arte e das suas relações com a realidade.

A forma artística, assim entendida, é, pois, essencialmente, "matéria formada", sem que isto signifique que seja puro traçado físico: dizer que a forma é matéria formada significa dizer que ela é, de per si, um conteúdo, um "conteúdo expresso", para usar o termo de Pareyson. Longe de sinalizar um formalismo, isto quer dizer que, na forma artística, tudo está carregado de significação, até as inflexões estilísticas mais discretas, enfim, tudo é significado. Dizer, pois, que a forma é matéria formada é o mesmo que dizer 
que ela é coincidência perfeita de forma e conteúdo: matéria formada é matéria humanizada, espiritualizada, impregnada de significado e de expressividade. Observe-se que essa identidade não é apenas entre forma e conteúdo, mas entre forma, entendida como matéria formada, e conteúdo, entendido como conteúdo expresso, o que pode ser traduzido em uma fórmula bastante ilustrativa:

\section{forma $=$ matéria formada $=$ conteúdo expresso}

A identidade deve-se, aqui, ao fato, já assinalado, de que tudo que integra, propriamente, a composição da forma artística ali está enquanto já assumido pelo gesto formativo do artista e em submissão à lei orgânica que presidiu todo o processo. ${ }^{7}$

A obra de arte apresenta-se, então, como uma contração orgânica de valores diversos, dotada de legalidade interna, de autônoma consistência e, ao mesmo tempo, de uma fundamental ligação com a realidade de onde nasce. Mas tudo isso, vale insistir, porque ela já emerge de suas circunstâncias com uma especificação própria.

Assim entendida, a forma artística apresenta-se como acabamento de uma gênese formativa que ela mesma dirige e que nela se inclui de modo indelével. Esse acabamento, evidentemente, não é algo que vem de acréscimo (como acontece, por exemplo, quando se faz consistir o problema artístico em dar uma forma estética a um dado conteúdo), mas subentende uma teleologia interna, explicada por Pareyson como uma atuação da própria obra como formante, bem antes de se concluir como forma formada. Entenda-se que essa relação dialética entre forma formante e forma formada não é auto-suficiente, pois só se torna de fato viva e eficaz com a intervenção pessoal do artista, resolvendo-se, então, em uma dialética entre a livre iniciativa do artista e a teleologia interna do êxito.

Em suma, o que Pareyson está pretendendo ressaltar é, primeiramente, que a obra de arte é expressiva e comunicativa não meramente quando toma o homem e seu tempo como assunto ou tema de discurso, mas enquanto os concretiza em si como modo: modo de formar que singulariza a obra e define o seu modo de ser. O discurso primeiro da arte, portanto, aquele que lhe é próprio, diz respeito a ela mesma: não é algo “(...) que se encontra atrás, ou dentro, ou sobre, ou além do [seu] aspecto sensível (...), mas é o seu próprio rosto físico, todo evidente na sua insondável dimensão espiritual". 8

7 Cf. PAREYSON, 1991, p. 13-55.

8 PAREYSON, 1997, p. 120. 
Assim sendo, compreender uma obra de arte não significa apenas explicitar um significado que transcende o seu corpo físico (como se a obra não passasse de um simples meio, um simples veículo cognoscitivo à espera de explicitação, e como se compreender fosse possuir de uma vez por todas a sua insondável realidade física e espiritual), mas, mais precisamente, interpretá-la, entrar em diálogo com ela, responder ao seu vivo apelo, quer dizer, ao vivo apelo que ela própria é, enquanto fundadora de um mundo que nasce com ela. Trata-se, enfim, de reconhecê-la, ao mesmo tempo, como uma forma e um mundo: “(...) uma forma que não exige valer senão como pura forma e um mundo espiritual que é um modo pessoal de ver o universo". 9 Mas só se pode vê-la como tal quando se tem presente a sua organicidade e o seu caráter dinâmico e processual. São esses fatores que atestam a alteridade a e irredutibilidade da forma artística relativamente aos pré-condicionamentos de qualquer natureza e que evidenciam o seu caráter hermenêutico e ontológico: hermenêutico, no sentido de que a sua interpretabilidade não é algo externo, secundário, posterior ao seu acabamento, mas é um aspecto, constitutivo de sua gênese interna; ontológico, no duplo sentido de que a) é produto do agir de uma pessoa e, assim como esta, está em relação com o ser, ${ }^{10}$ b) de que se impõe, ela própria, como uma realidade, cujo fundamento reside nela mesma, na sua própria constituição interna, e não em algo já dado e pré-constituído.

Como se vê, estamos diante de uma estética que estabelece um vínculo essencial e indivisível entre os três momentos fundamentais da experiência da arte: a gênese, a forma acabada e a interpretação. São momentos que se interligam na própria obra - na medida em que esta, no ato mesmo em que se apresenta como conclusão de um processo formativo, exibe-se como abertura a inesgotáveis interpretações, atuando como lei diretiva, primeiramente, para o autor e, posteriormente, para o intérprete. Dentre outras coisas, o reconhecimento dessa íntima vinculação obriga-nos a um outro reconhecimento fundamental: de que a forma artística, bem mais do que ser expressão de um mundo acabado, é, na sua essência, um começo, uma abertura permanente ao diálogo, no sentido de que é uma fonte inesgotável de significados, capazes de iluminar, de modo sempre novo a realidade à sua volta e de modificar qualitativamente o lugar do homem e das coisas dentro dessa realidade. 


\section{Considerações finais}

$\mathrm{Na}$ argumentação de Marcuse sobre a autonomia da arte, identifiquei como pontos problemáticos a presença de certos resíduos conteudistas e o uso de um modelo explicativo predominantemente "fundacionalista". Penso que é, sobretudo, em virtude desses fatores que ele não consegue garantir teoricamente a autonomia e o valor de verdade da arte, que tão zelosamente quer afirmar: só pode explicá-los mediante uma relativização dos mesmos a uma estrutura mais ampla - as relações sociais estabelecidas - que, supostamente, deteria os móveis de sua explicitação.

Esse tipo de enfoque debilita o valor de verdade da obra de arte e o fundamental reconhecimento do seu caráter instaurador, impedindo uma adequada visão da experiência estética como uma real experiência de transcendência (tanto para quem a produz, quanto para quem a interpreta) e, por conseguinte, uma adequada avaliação do poder, que a arte, todavia, possui, de pôr em crise todo um modo de existência do homem no mundo.

Prova disto é que, embora a teoria marcuseana pareça funcionar relativamente bem, no que diz respeito à literatura de períodos anteriores, aos quais se refere explicitamente, é posta em xeque pelas poéticas da vanguarda artística nascente à sua época. Do prisma sociológico por ele adotado, não há como avaliar adequadamente o sentido intrinsecamente revolucionário das renovações formais promovidas por essas poéticas. Para tanto, seria preciso perceber que renovar as formas da arte significa renovar as relações humanas nos seus mais diversos níveis. E isto nenhuma estética sociológica consegue explicar satisfatoriamente.

Desse modo, o estatuto hermenêutico e ontológico da arte resulta ambíguo, na teoria de Marcuse: por um lado, é consignada à arte uma função insubstituível na esfera das relações humanas; por outro, ela fica destituída de uma verdadeira originalidade, de uma verdadeira novidade, na medida em que o reconhecimento do seu valor de verdade acaba por coincidir com o reconhecimento da sua funcionalidade social, o que a transforma em algo, que só é levado a sério devido ao seu poder de desempenhar certas funções tidas como primordiais. Afinal, se compreender e fruir uma obra de arte significa compreender aquilo a que ela remete, então a sua verdade não é o que ela concretamente é, mas o seu significado em relação à situação histórica de que é considerada como uma manifestação. $\mathrm{O}$ que conta para essa teoria parece ser a funcionalidade que a obra pode ter, o que transforma o nosso encontro com ela em um momento provisório.

As implicações desse modelo explicativo são, na verdade, bem mais problemáticas, na medida em que acarretam um esvaziamento do crucial 
problema da interpretação: só haverá um único modo de colher corretamente a obra na sua verdade e é, precisamente, compreender o fundamento a que ela remete.

$\mathrm{Na}$ estética de Pareyson, pelo contrário, a autonomia da obra de arte revelou-se um traço constitutivo dela mesma, intrinsecamente ligado à sua especificação como arte.

Três aspectos de sua teoria revestem-se, a meu ver, de valor decisivo para a sustentação teórica dessa autonomia:

1. a identidade de forma, matéria e conteúdo, na obra de arte;

2. a alteridade da obra frente a seu autor e seu tempo, enquanto se apresenta, ao mesmo tempo, como lei e resultado do seu próprio processo de formação;

3. a polaridade contínua entre acabamento e processualidade, pela qual a forma acabada pode colocar-se, não apenas como acabamento e resultado (o que faria dela um mero objeto de explicitação), mas como abertura a um fluxo interminável de interpretações, ao longo da história.

No que diz respeito mais diretamente à questão das relações entre arte e sociedade, é sem dúvida decisivo o argumento pareysoniano de que a obra de arte nasce com um preciso condicionamento, mas já especificada como arte. Isto quer dizer: 1) que longe de se especificar como transformação estética de um dado conteúdo, a forma estética já nasce com uma especificação formativa (vale dizer: nasce já como "conteúdo expresso"); 2) que o seu poder de exercer esta ou aquela função, o seu potencial revolucionário e libertário, enfim, são decorrências dessa autonomia e não fatores determinantes em relação à mesma.

Em suma: se a obra de arte pode exercer tais funções, sem com isso se comprometer na sua autonomia e no seu valor, é justamente porque, antes, conseguiu ser arte, e não o contrário.

Todos esses fatores permitem ver na teoria de Pareyson uma decisiva abertura hermenêutica e ontológica, não só no sentido de possibilitar uma leitura integral do fenômeno arte e uma satisfatória compreensão da sua autonomia, mas também no sentido de descortinar a possibilidade de se repensar, sobre bases mais consistentes, a questão do estatuto ontológico da arte, enquanto alteridade irredutível, não dedutível e não explicável por condições preexistentes. Nesses traços, penso eu, consiste um dos contributos mais significativos da ontologia estética pareysoniana. 


\section{Referências}

MARCUSE, Herbert. A dimensão estética. São Paulo: Martins Fontes, 1986.

PAREYSON, Luigi. Os problemas da estética. 3. ed. São Paulo: Martins Fontes, 1997. . Conversaciones de estética. Madrid: Visor, 1988.

. Estetica: teoria della formatività. 5. ed. Milão: Tascabili Bompiani, 1991. 